\title{
EXPERIMENTAL TESTING CORRELATION WITH NUMERICAL MESO-SCALE MODELLING OF CFRP STRUCTURES AND THE SIGNIFICANCE TO VIRTUAL CERTIFICATION OF AIRFRAMES
}

\author{
C. N. MOULKIOTIS ${ }^{1}$, I. K. GIANNOPOULOS ${ }^{1}$, E. E. THEOTOKOGLOU ${ }^{2}$ \\ ${ }^{1}$ Centre of Excellence for Aeronautics, School of Aerospace, Transport and Manufacturing, \\ Cranfield University, Cranfield \\ MK43 0AL, UK \\ C.Moulkiotis@cranfield.ac.uk, https://www.linkedin.com/in/christos-moulkiotis/ \\ i.giannopoulos@cranfield.ac.uk, https://www.cranfield.ac.uk/people/dr-ioannis-giannopoulos-502415 \\ ${ }^{2}$ Department of Mechanics, Laboratory of Testing and Materials, School of Applied Mathematical and \\ Physical Sciences, National Technical University of Athens \\ GR-157 73, Greece \\ stathis@central.ntua.gr,http://www.semfe.ntua.gr/el/faculty-members/theotokoglou
}

Key words: CFRP, strength prediction, finite element analysis, virtual testing, LaRC05, progressive damage

\begin{abstract}
The design of structural components has altered fundamentally since laminated composites were proved excellent candidate materials in aerospace applications. The key aspects rendering CFRPs preferable to metals, are mostly their significantly higher specific mechanical properties, and the design flexibility through the stacking sequence selection. However, the currently in use limit and polynomial failure criteria, are inadequate to accurately predict all experimentally observed failure modes and damage specificities of the lamina individual constituents, imposing difficulties in the numerical certification of airframe composites. Thus, component and lamina-level testing are sometimes inevitable, requiring industrial resources which are expensive as well as environmentally costly. For that reason, virtual testing could be more promising in substituting real experimental testing, if conducted under advanced failure criteria which better describe the nature of failure. In this study, the open hole tensile (OHT) test has been simulated under the LaRC05 phenomenological failure criterion, with embedded strain-based progressive damage material behavior. A relatively common composite material in aerospace structures has been selected, IM7 8552 of Hexcel, to compare the numerical strength predictions with its corresponding experimental values. The simulations carried out are based on a standard test method by ASTM international, which address the standardisation of strength tests of polymer matrix composite laminates. The, model was created in ABAQUS/Explicit under the VUMAT user subroutine. The resulted predictions have been found to well - correlate with the testing data, irrespective the specimen stacking sequence.
\end{abstract}




\section{INTRODUCTION}

The nature of Fibre Reinforced Plastics (FRPs) as multi-face materials, introduces plethora of damage and failure modes, which have been extensively observed and reported since continuous fibre composites emerged [1]. Lamina-based failure modes include complex fibre, matrix and interface types of damage as well as interactions among them, which can significantly degrade the material structural performance when loaded in or out-of-plane. Moreover, multifaced material damage and fracture may occur in a variety of in-service failure of structural composites [2], emphasising profoundly how challenging their design procedure is, especially when failure must be predicted under stress-based criteria. Even though limit and polynomial failure criteria such as Max Stress, Tsai-Hill and Tsai-Wu provide easiness in failure assessment as well as account for its directionality, the nature of failure is totally disregarded [3], leaving most of the potential damage modes unpredicted. On the other hand, physically based and phenomenological failure criteria, were derived and are constantly reamended, to effectively capture many of the micro-scale material specificities, providing the design flexibility of exploiting laminae and laminate level parameters [4].

Furthermore, failure modes in FRPs fell into three general categories according to [5]; translaminar, intralaminar and interlaminar. Fibre fracture is related with translaminar failure, whereas matrix cracks and generally through the thickness failures between the fibres, are considered as intralaminar failures. Finally, interlaminar failure refers to delaminations or cracks between the laminate plies. Accounting the FRP's behavior to fail progressively,

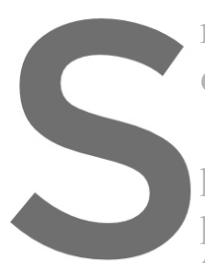
researchers have devolo of damage as per the in

Following this approa presented in [4], further purpose finite element to be extended; so that residual strengths, damage, and ultimate

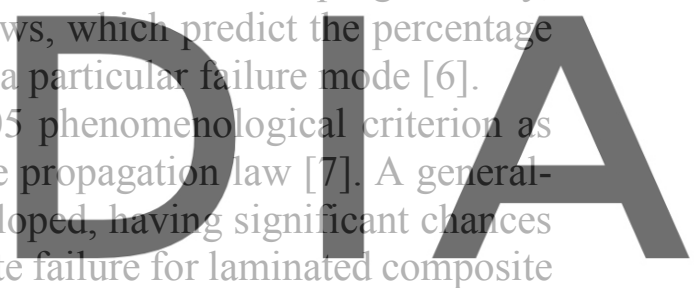
structures can be numerically estimated. For the time being, the method has been found to

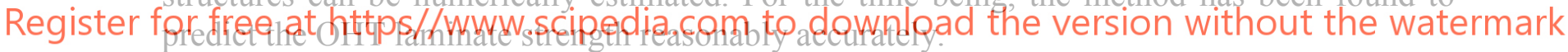

\section{MATERIAL AND EXPERIMENTAL OHT DATA}

IM7 8552 of Hexcel [8] has been selected for the purposes of the comparison study between the numerical and the experimental results. The material properties are reported in Table 1.

Table 1: IM7 8552 basic lamina properties assuming transverse isotropy, [4]; [8]; [9].

\begin{tabular}{cc} 
Lamina Properties & IM7 $8552\left(t_{p}=0.183 \mathrm{~mm}, \rho=1570 \mathrm{~kg} / \mathrm{m}^{3}\right)$ \\
\hline Moduli (MPa) & $E_{1}=158510, E_{2}=8963.1, G_{12}=\mathrm{G}_{13}=4688.4, G_{23}=3090.7$ \\
\hline Poisson Ratio & $v_{12}=0.316, v_{13}=0.316, v_{23}=0.45$ \\
\hline Tensile Strength $(\mathrm{MPa})$ & $X_{T}=2500.6, Y_{T}=Z_{T}=64$ \\
\hline Compressive Strength $(\mathrm{MPa})$ & $X_{C}=1716.3, Y_{C}=Z_{C}=285.7$, \\
\hline Shear Strength $(\mathrm{MPa})$ & $S_{L}=91.1, S_{T}=107.6$ \\
\hline Fracture Toughness $\left(\mathrm{kJ} / \mathrm{m}^{2}\right)$ & $G_{I C}=0.212, G_{I I C}=0.774, G_{f t}=92, G_{f C}=80$
\end{tabular}


Three stacking sequences have been examined in this study, the strengths of which are recorded in Table 1, whereas Figure 1 depicts the specimen as well as FE model dimensions as reported in [8]. The experiments were conducted in accordance with the ASTM D5766 standard, which governs the testing method for the determination of the OHT strength of polymer matrix composite laminates [10].

Table 2: IM7 8552 OHT properties, [8].

\begin{tabular}{cccc} 
Configuration & Stacking Sequence & $\begin{array}{c}\text { OHT Strength } \\
(\mathrm{MPa})\end{array}$ & $\begin{array}{c}\text { Equivalent } \\
F_{\max }(\mathrm{N})\end{array}$ \\
\hline$[50 / 40 / 10]$ & {$[0 / 45 / 0 / 90 / 0 /-45 / 0 / 45 / 0 /-45]_{\mathrm{s}}$} & 597.0 & 83197.0 \\
\hline$[25 / 50 / 25]$ & {$[45 / 0 /-45 / 90]_{2 \mathrm{~S}}$} & 320.8 & 45350.4 \\
\hline$[10 / 80 / 10]$ & {$[45 /-45 / 0 / 45 /-45 / 90 / 45 /-45 / 45 /-45]_{\mathrm{s}}$} & 301.0 & 41940.2 \\
\hline
\end{tabular}

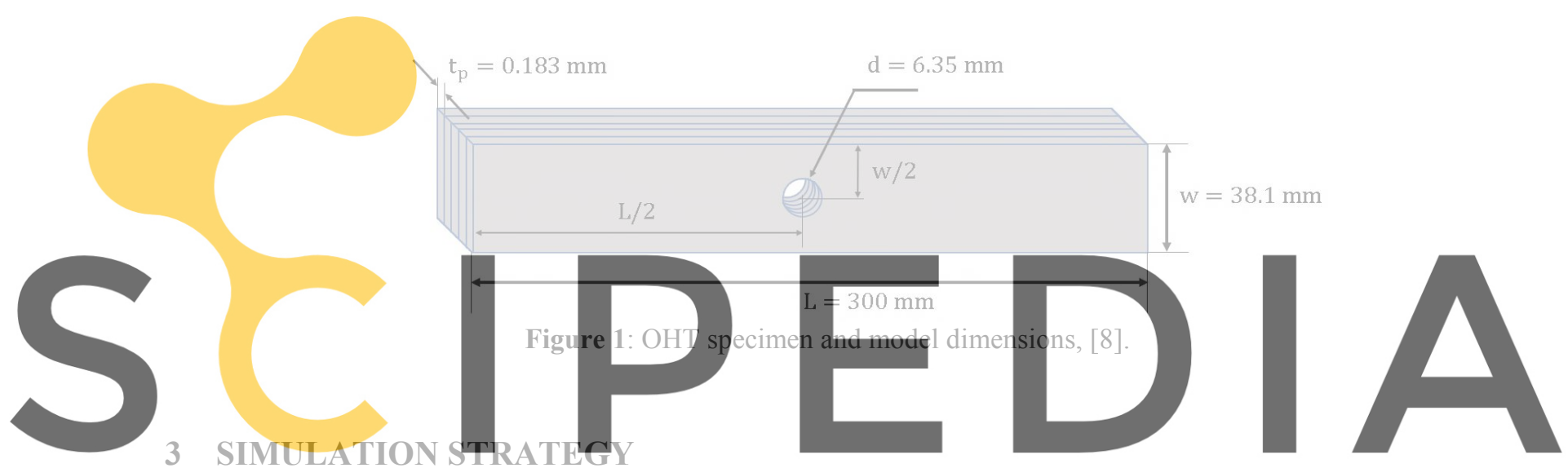

Register forl freẹl latehithipstipawww.scipedia.com to download the version without the watermark

The LaRC05 phenomenological criterion developed by NASA researchers [4], generally predicts fibre failure and matrix crack, both in tension and compression. The criterion, in contrast with the common failure criteria, can additionally estimate three different damage modes; fibre kink, fibre split and the three-dimensional prediction of the matrix crack fracture plane. Fibre tensile failure is calculated through the limit failure index of the Maximum Stress criterion, as its predictions better fit the researchers' experimental results [4]. With regards to fibre kink-split damage modes, the criterion estimates fibre compressive failure at a point within the lamina, located on a plane rotated about the lamina principal axis- 1 by an arbitrary angle $\psi$. However, failure is examined along the direction of the kinked fibres, from which the angle of fibre misalignment $\varphi$ is formed. Hence, the corresponding failure index uses the stresses expressed at the initial lamina coordinate system, in a formula derived by two consecutive transformations of the stress tensor as per the direction cosines containing the information of the coordinate systems. The angle $\varphi$ exists because of an initial fibre misalignment after a manufacturing error, superimposed by an additional angle generated by the examined stress field. The angle $\psi$ must be identified so that the failure index is maximised $\left(0^{\circ} \leq \psi<180^{\circ}\right)$. Similarly, the matrix crack fracture plane, defined by the angle $a\left(0^{\circ} \leq a<180^{\circ}\right)$, can be 
determined with the same manner as the kink-band plane. The traction components of the fracture plane are examined by the modified Mohr-Coulomb matrix crack failure index, which assesses the onset of failure. The last two damage modes are schematically represented in Figure 2. Finally, LaRC05 failure indexes are briefly presented through the equations (1)-(3). The indexes highlight the onset of failure when their corresponding values are unity.

$$
\begin{gathered}
F I_{F T}=\frac{\sigma_{1}}{X_{T}} \leq 1 \\
F I_{F C}^{\text {Kink }}=F I_{F C}^{S p l i t}=\left(\frac{\sigma_{23}^{m}}{S_{T}^{i S}-\eta_{T} \sigma_{2}^{m}}\right)^{2}+\left(\frac{\sigma_{13}^{m}}{S_{L}^{i S}-\eta_{L} \sigma_{2}^{m}}\right)^{2}+\left(\frac{\left\langle\sigma_{2}^{m}\right\rangle}{Y_{T}^{i s}}\right)^{2} \leq 1
\end{gathered}
$$

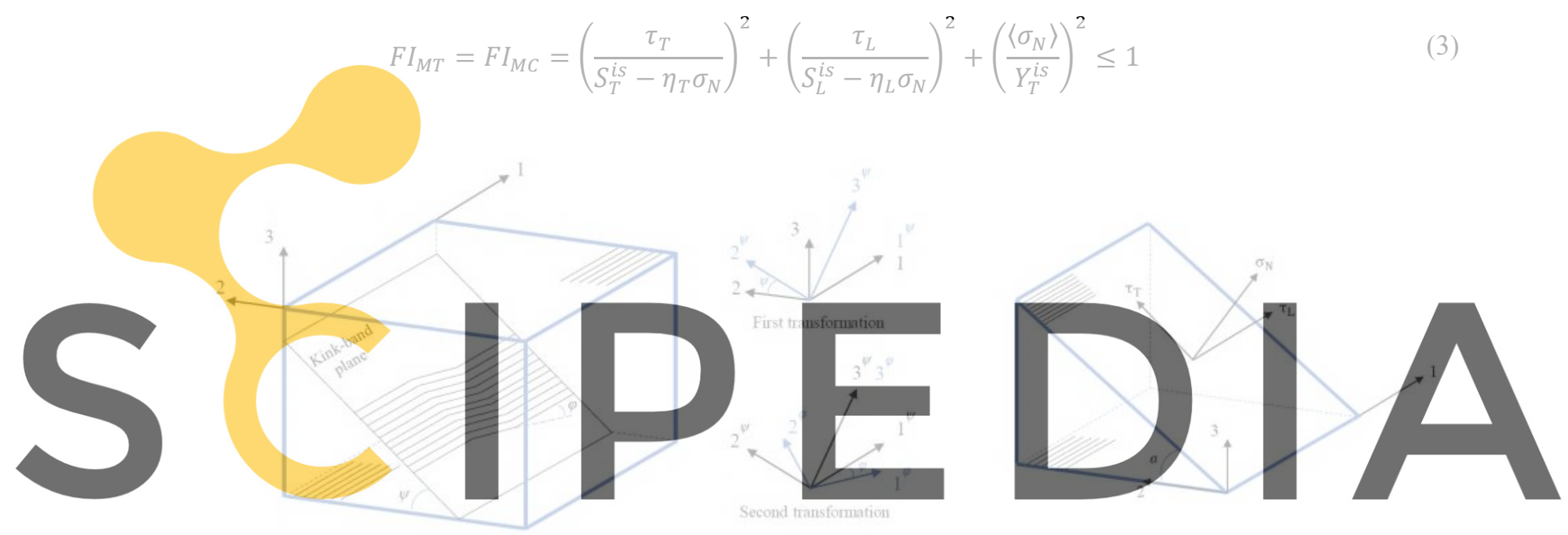

Register for free at https//www.scipedia.com to download the version without the watermark Figure 2: Predicted damage modes of the LaRC05 failure criterion,

a) kink-band plane, b) matrix fracture plane and respective traction components, [4].

Where $Y_{T}^{i s}, S_{T}^{i s}$ and $S_{L}^{i s}$ are the transverse normal, transverse shear and longitudinal shear 'insitu' stresses, respectively. Finally, fibre splitting occurs when the along the fibres compressive strength is between $0>\sigma_{1}>-\frac{X_{C}}{2}$, whereas fibre kinking is predicted if $-\frac{X_{C}}{2}>\sigma_{1}>-X_{C}$.

\section{2 'In-situ' strengths}

Table 3 presents the equations describing the 'in-situ' effect, firstly observed by Parvizi et al [11]. The 'in-situ' theory also reported in [12], estimates an increased value of the transverse normal, transverse shear and longitudinal shear stresses, depending on the boundary conditions enforced by the constraining plies, which affect the fracture mechanics of the examined lamina. Moreover, the strength estimations have been experimentally observed as disproportional to the lamina thickness, but reaching a plateau for thick laminae. In general, the 'in-situ' effect applies to every lamina constituting the investigated laminate, and the formulations are distinguished 
into three different categories:

- The outer plies, constrained only once by a ply of different orientation.

- The thin embedded plies, which are constrained at both the upper and lower lamina surfaces by plies of different orientation.

- The thick embedded plies, defining the thickness threshold at which the strength remains approximately constant.

Table 3: 'In-situ' strength formulae assuming shear non linearity as proposed by Tsai-Hahn [12]; [13]; [14].

Thin embedded

Thick embedded

Outer

\begin{tabular}{|c|c|c|c|}
\hline$Y_{T}^{i s}$ & $\sqrt{\frac{8 G_{I C}}{\pi t_{p} \Lambda_{22}^{\boldsymbol{O}}}}$ & $1.12 \sqrt{2} Y_{T}$ & $1.79 \sqrt{\frac{G_{I C}}{\pi t_{p} \Lambda_{2}^{o}}}$ \\
\hline$\varphi$ & $\frac{48 G_{I I C}}{\pi t_{p}}$ & $\frac{12 S_{L}^{2}}{G_{12}}+18 \beta S_{L}^{4}$ & $\frac{24 G_{I I C}}{\pi t_{p}}$ \\
\hline$S_{L}^{i s}$ & & $\sqrt{\frac{\sqrt{\left(1+\beta \varphi G_{12}^{2}\right)}-1}{3 \beta G_{12}}}$ & \\
\hline
\end{tabular}
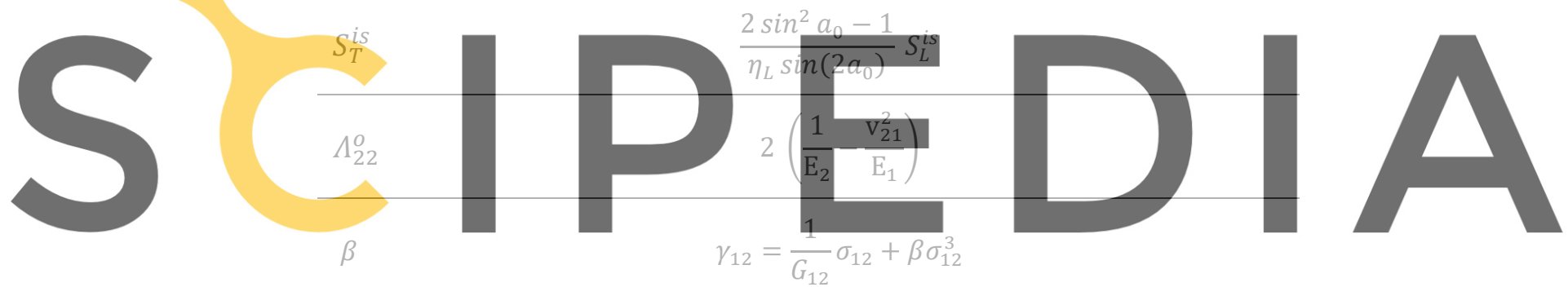

Register for free at https//www.scipedia.com to download the version without the watermark

The parameter $\beta=2.44 \cdot 10^{-8}$, is a typical value for CFRPs taken from [12], after the TsaiHahn equation matched the experimental results of the authors. In the case of the embedded plies, the 'in-situ' strengths are predicted from the maximum value between the formulations corresponding to thick and thin plies, since the threshold differs for each FRP material. The strength predictions found for the IM7 8552 CFRP material for all cases defined by the stacking sequences of Table 2, are recorded below.

Table 4: 'In-situ' strengths of IM7 8552 CFRP.

\begin{tabular}{ccccc}
\hline In-situ Strength & Outer & Embedded, $t_{p}$ & Embedded, $2 t_{p}$ & Initial \\
\hline$Y_{T}^{i s}(\mathrm{MPa})$ & 72.8 & 115.0 & 101.4 & 64.0 \\
\hline$S_{L}^{i s}(\mathrm{MPa})$ & 97.8 & 120.4 & 112.6 & 91.1 \\
\hline$S_{T}^{i s}(\mathrm{MPa})$ & 115.5 & 142.2 & 133.0 & 107.6 \\
\hline
\end{tabular}




\subsection{Estimation of material damage}

The moment failure initiates, the material stiffness matrix will be degraded as per the bilinear progressive damage law of Figure 3, which describes the translaminar and intralaminar damage evolution. Depending on the failure mode, the method requires the equivalent stress, strain, and fracture toughness given from equations (4)-(13), for predicting the damage variables causing the material degradation governed by the equations (14)-(20).

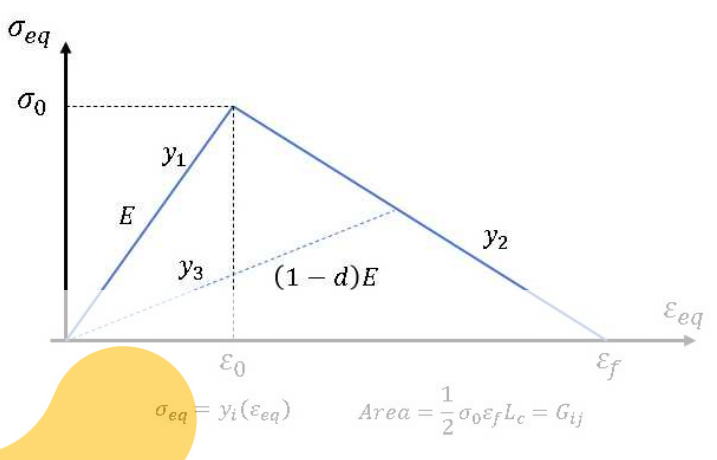

a)

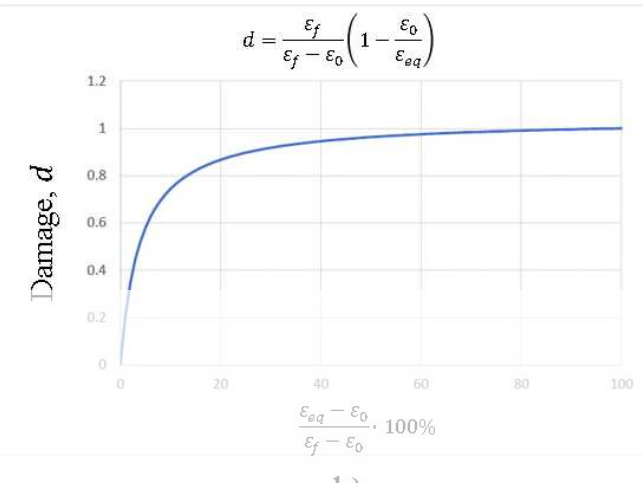

b)

Figure 3: Progressive damage law, a) bilinear material degradation, b) damage evolution, $L_{c}$ : characteristic element length.
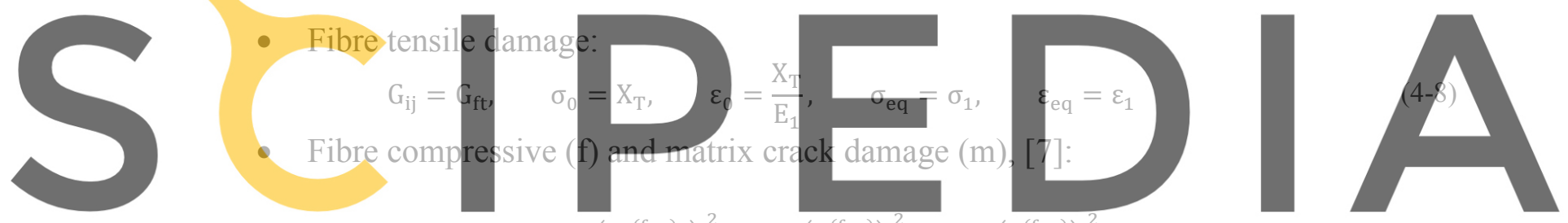

(9)

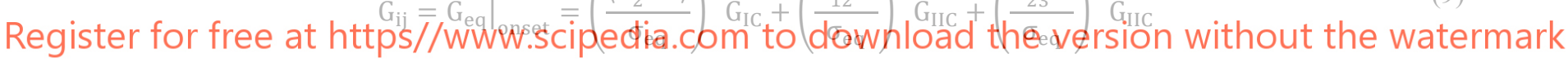

$$
\begin{gathered}
\varepsilon_{\mathrm{eq}}=\sqrt{\left(\left\langle\varepsilon_{2}^{(\mathrm{f}, \mathrm{m})}\right\rangle\right)^{2}+\left(\varepsilon_{12}^{(\mathrm{f}, \mathrm{m})}\right)^{2}+\left(\varepsilon_{23}^{(\mathrm{f}, \mathrm{m})}\right)^{2}} \\
\sigma_{\mathrm{eq}}=\sqrt{\left(\left\langle\sigma_{2}^{(\mathrm{f}, \mathrm{m})}\right\rangle\right)^{2}+\left(\sigma_{12}^{(\mathrm{f}, \mathrm{m})}\right)^{2}+\left(\sigma_{23}^{(\mathrm{f}, \mathrm{m})}\right)^{2}} \\
\varepsilon_{0}^{(\mathrm{f}, \mathrm{m})}=\left.\varepsilon_{\text {eq }}\right|_{\text {onset }} \\
\sigma_{0}^{(\mathrm{f}, \mathrm{m})}=\left.\sigma_{\text {eq }}\right|_{\text {onset }}
\end{gathered}
$$

- Degradation of the material stiffness matrix (plane stress conditions):

$$
\begin{array}{ll}
\mathrm{dQ}_{11}=\left(1-\mathrm{d}_{\mathrm{f}}\right) \mathrm{Q}_{11} & \mathrm{~d}_{\mathrm{f}}=1-\left(1-\mathrm{d}_{\mathrm{ft}}\right)\left(1-\mathrm{d}_{\mathrm{fc}}\right) \\
\mathrm{dQ}_{22}=\left(1-\mathrm{d}_{\mathrm{f}}\right)\left(1-\mathrm{d}_{\mathrm{m}}\right) \mathrm{Q}_{22} & \mathrm{~d}_{\mathrm{m}}=1-\left(1-\mathrm{d}_{\mathrm{mt}}\right)\left(1-\mathrm{d}_{\mathrm{mc}}\right) \\
\mathrm{dQ}_{12}=\left(1-\mathrm{d}_{\mathrm{f}}\right)\left(1-\mathrm{d}_{\mathrm{m}}\right) \mathrm{Q}_{12} & \mathrm{~d}_{\mathrm{s}}=1-\left(1-\mathrm{d}_{\mathrm{ft}}\right)\left(1-\mathrm{d}_{\mathrm{fc}}\right)\left(1-0.9 \mathrm{~d}_{\mathrm{mt}}\right)\left(1-0.5 \mathrm{~d}_{\mathrm{mc}}\right) \\
\mathrm{dQ}_{33}=\left(1-\mathrm{d}_{\mathrm{s}}\right) \mathrm{G}_{12} &
\end{array}
$$




\subsection{FE model}

Simplifying the case-study assuming plane-stress conditions, the ABAQUS OHT model was created by conventional finite-strain shell elements of reduced integration (S4R). The model was partitioned for better mesh control as Figure 4 indicates. The region of interest was meshed by a two-way bias, creating smaller elements around the hole, to efficiently capture the stress concentration of the area. Regions of insignificant information were meshed either by a constant element size setting, or by embedded algorithms of ABAQUS. Moreover, the left vertical boundary of the model was pinned, whereas only a tensile, linearly increased displacement input was enforced at its right side. Consequently, the circularly partitioned area of the model, contained slightly distorted elements of 1.096 maximum aspect ratio.

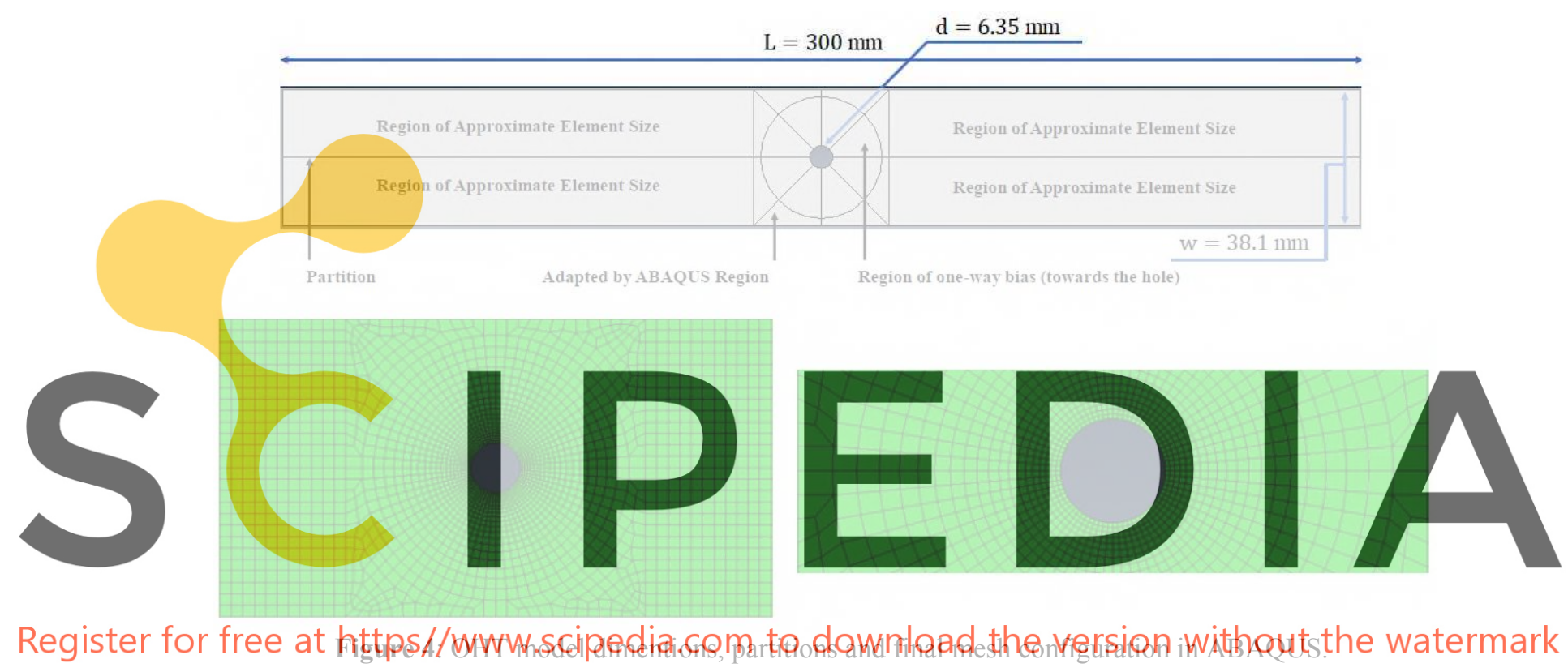

In addition, the in-situ effect slightly alters the way that the laminate was introduced to the software. The theory can only be applied if consecutively stacked plies of the same orientation are merged as one lamina of equivalent thickness, with its properties maintained apart from its affected strengths $\left(Y_{T}^{i s}, S_{T}^{i s}\right.$ and $\left.S_{L}^{i s}\right)$. For the investigated stacking sequences, this occurs at planes of major and repeated lay-up symmetry, yielding embedded plies of double the thickness. Lastly, the model was finalised through a two-factorial parametric analysis, which defined the prementioned mesh layout and the applied time increment, so that the forcedisplacement curve output is a product of solution convergence.

\subsection{VUMAT user subroutine}

The user subroutine was developed in FOTRAN 94 programming language, which is compatible with the FE software. Included, are the aforementioned equations governing the material response in failure initiation and damage evolution, whereas the material properties as well as the OHT model were introduced in ABAQUS CAE. Figure 5 demonstrates how the 
software interacts with the VUMAT LaRC05 2D/ Progressive subroutine, which calculates the stresses at every material point and enforces material degradation or element deletion when it is appropriate.

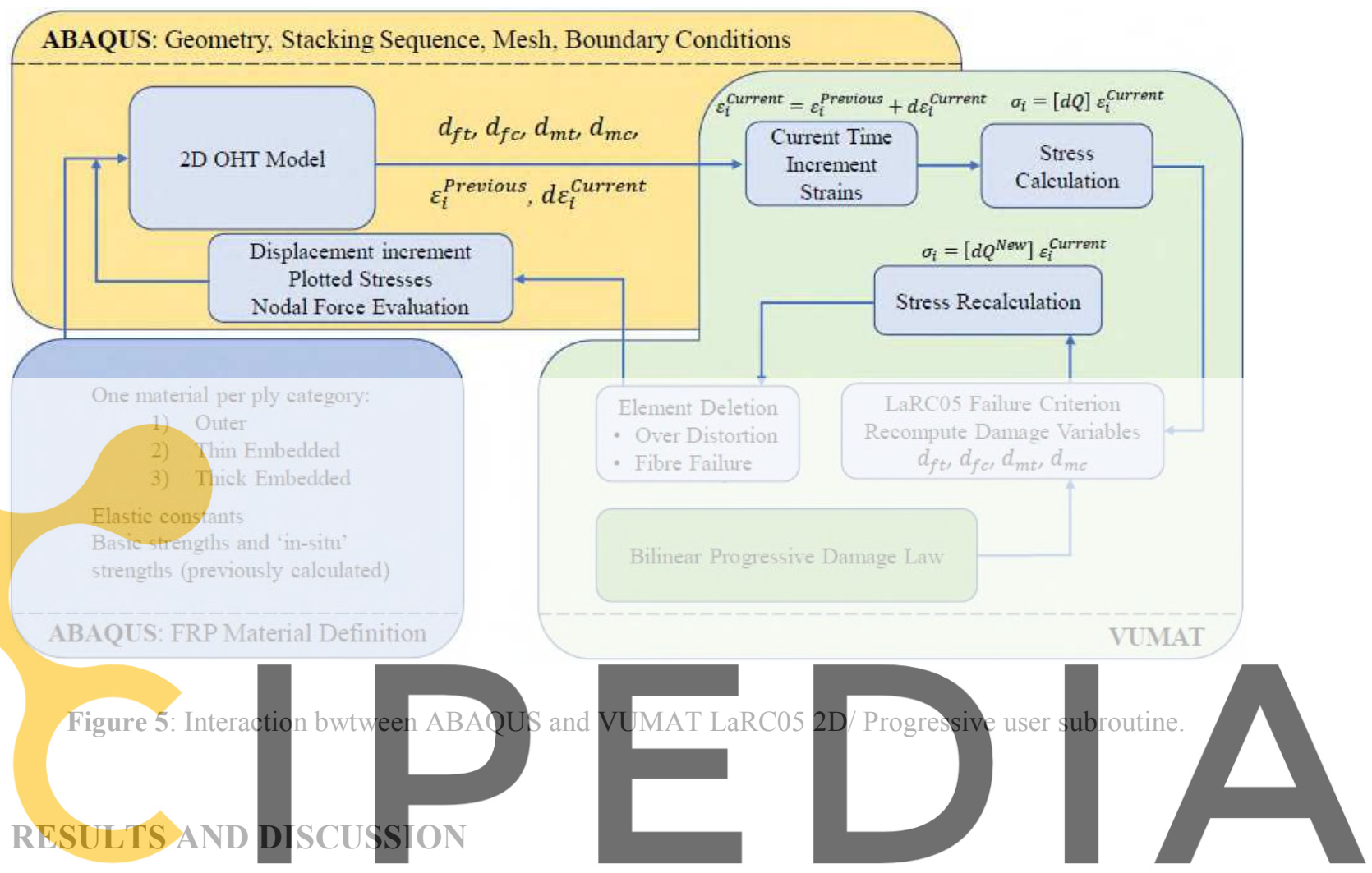

The maximum force $\left(F_{\max }\right)$ prediction emerged at absolute laminate fracture, after the

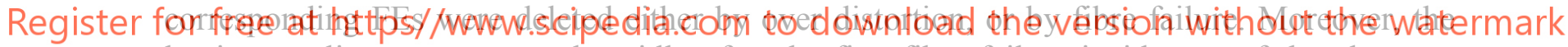
laminate split event, occurred rapidly after the first fibre failure incidences of the elements located near the hole, observation that complies with the brittle nature of CFRPs as well as with the results of the relevant study of Zhang et al [7].

As Figure 6 depicts, the model predicted matrix cracking as first ply failure, appeared at the hole boundary. As the OHT model was further elongated, the matrix crack damage mode developed and affected predominantly nearby elements (Figure 6-b). Matrix damage further accumulated around the hole until a final stage (Figure 6-d), after which fibre failure initiated and rapidly expanded due to the high stress concentration imposed by the material nonhomogeneity characterized by severe material degradation.

Figure 7 compares the ABAQUS outputs presented as force displacement curves, with the ultimate OHT strengths reported by Hexcel for the different laminate configurations of Table 2 [8]. The figure proves that the VUMAT LaRC05 2D/ Progressive method is consistent in predicting the laminate strength with considerable accuracy, irrespective the specimen stacking sequence. Moreover, the simulation errors have been found about $2 \%, 6 \%$, and $9 \%$ for the [50/40/10], [10/80/10] and [25/50/25] laminate configurations, respectively. Finally, the laminate failure modes observed in ABAQUS, are in accordance with those mentioned in the ASTM standard [15], for every examined case. 

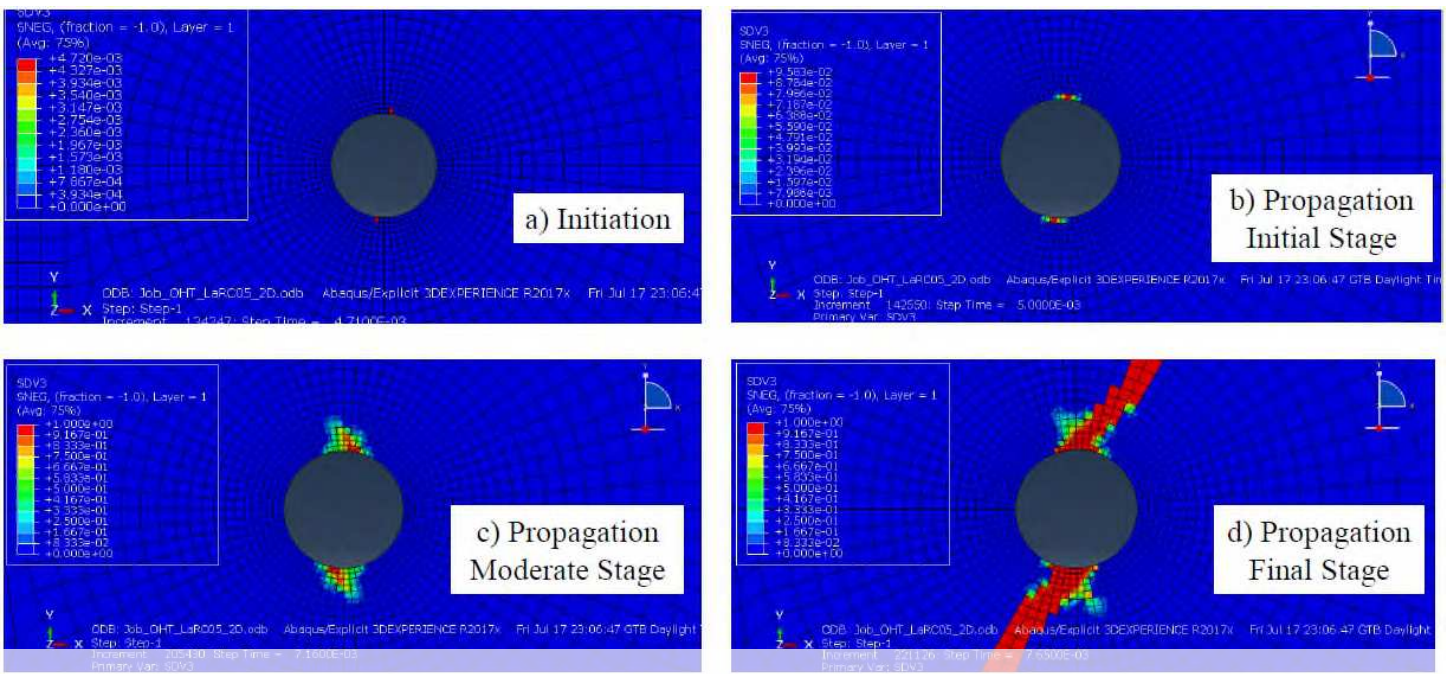

Figure 6: Representation of matrix crack initiation and propagation at several time frames [10/80/10].

\section{Numerical and experimental data correlation}

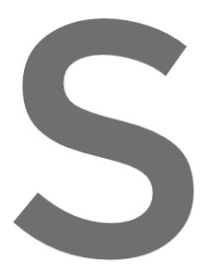

Register for free

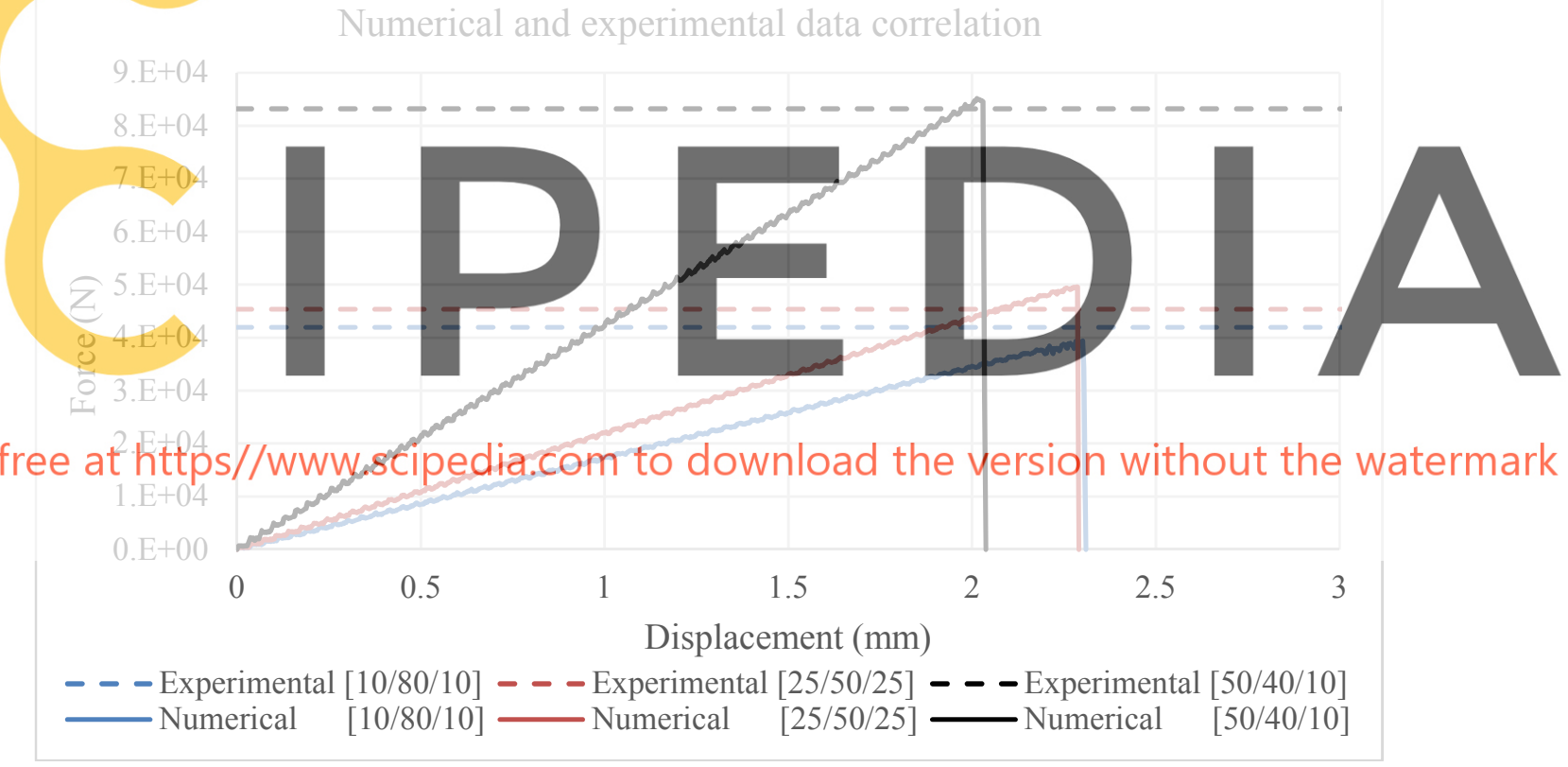

Figure 7: Comparison study between numerical and testing OHT data of the IM7 8552 CFRP materlal for diferent lamina stacking sequences.

Table 5: Simulation errors.

\begin{tabular}{cccc}
\hline \multirow{2}{*}{ Laminate } & \multicolumn{2}{c}{ Maximum Force, $F_{\max }(\mathrm{N})$} & \multirow{2}{*}{ Error $(\%)$} \\
\cline { 2 - 3 } & Numerical & Experimental, $[8]$ & \\
\hline$[50 / 40 / 10]$ & 85155.5 & 83197.0 & 2.35 \\
\hline$[25 / 50 / 25]$ & 49554.6 & 45350.4 & 9.27 \\
\hline$[10 / 80 / 10]$ & 39399.1 & 41940.2 & 6.05 \\
\hline
\end{tabular}


Shaping the understanding on how the failure criterion impacts the maximum force, a similar VUMAT user subroutine was created based on the Max Stress criterion. The outputs of the subroutines for the [25/50/25] laminate are compared in Figure 8-a, where a higher maximum force is predicted when the Max Stress criterion is considered. The VUMAT Max Stress 2D/ Progressive method overshoots the experimental strength value by $48.9 \%$, rendering the criterion highly inappropriate. However, the criteria share the same failure index and propagation law in fibre tension.

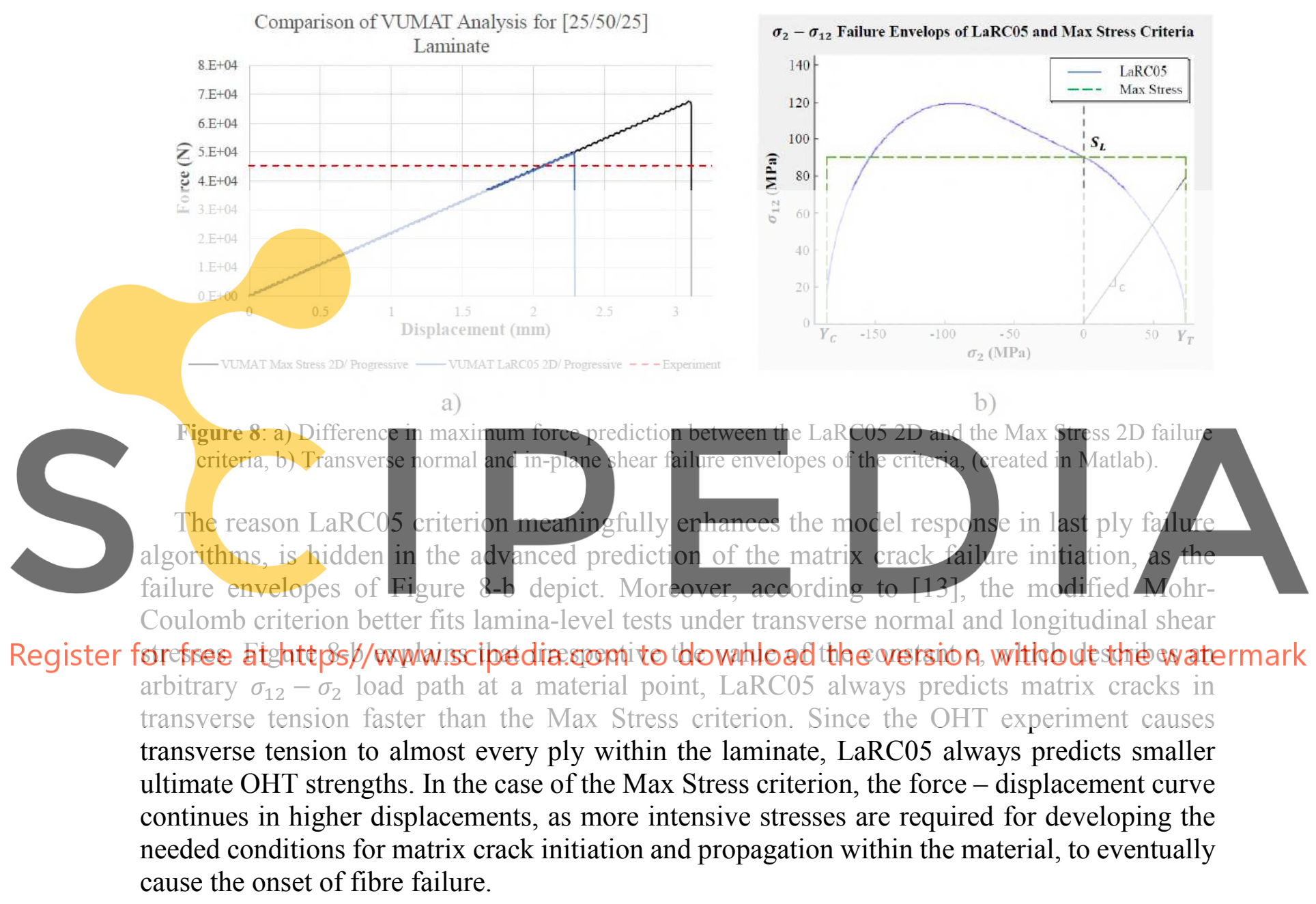

\section{CONCLUSIONS}

The use of phenomenological failure criteria substantially increases the design efficiency of laminated structures. The research demonstrates a method which effectively captures the failure incidences in generally orthotropic laminates, predicting valuable initial design parameters such as the OHT strength. Moreover, the introduction of the bilinear progressive damage law to simulate the material fracture, enhances the accuracy of high stress concentration applications. Finally, the outcome of this research shows that aerostructures may be virtually certified through FEA in the foreseeable future, should further effort is being deposited. 


\section{REFERENCES}

[1] Zimmermann, N. and Wang, P. H. (2020) 'A review of failure modes and fracture analysis of aircraft composite materials', Engineering Failure Analysis, 115, p. 104692. doi: 10.1016/j.engfailanal.2020.104692.

[2] Barbero, E. J. (2011) Introduction to Composite Materials Design. Second Edi. CRC Press. [3] Gutkin, R. (2010) Understanding and modelling failure of laminated composites. Imperial College London.

[4] Pinho, S., Darvizeh, R., Robinson, P., Schuecker, C. and Camanho, P. (2012) 'Material and structural response of polymer-matrix fibre-reinforced composites', Journal of Composite Materials, 46(19-20), pp. 2313-2341. doi: 10.1177/0021998312454478.

[5] Jollivet, T., Peyrac, C. and Lefebvre, F. (2013) 'Damage of Composite Materials', Procedia Engineering, 66, pp. 746-758. doi: 10.1016/j.proeng.2013.12.128.

[6] S T Pinho, C G D'avila, P P Camanho, L. I. and Robinson, P. (131AD) 'Progressive failure analysis of advanced composites'. UMEC Composite Materials, p. 2008.

[7] Zhang, D., Zheng, X. and Wu, T. (2019) 'Damage characteristics of open-hole laminated composites subjected to longitudinal loads', Composite Structures, 230, p. 111474. doi: 10.1016/j.compstruct.2019.111474.

[8] Marlett, K. (2011) 'Hexcel 8552 IM7 Unidirectional Prepreg 190 gsm \& 35\%RC Qualification Material Property Data Report, FAA Special Project Number SP4614WI-Q, NCAMO Test Report Number: CAM-RP-2009-015 Rev A'. Natianal Institute for Aviation Reaserch, pp. 1-238.

[9] Krueger, R. (2014) 'Finite Element Analysis of Composite Joint Configurations With Gaps and Overlaps'. Hampton, Virginia: NASA, National Institute of Aerospace, p. 60. doi: NASA/CR-2014-218284, NIA Report No. 2014-0619.

[10] D5766/D5766M - 11 (2018) 'Standard Test Method for Open-Hole Tensile Strength of Polymer Matrix Composite Laminates1'. ASTM, p. 7.

[11] A. Parvizi, K. W. G. \& J. E. B. (1978) 'Constrained cracking in glass fibre - reinforced epoxy cross-ply laminates', Journal of Materials Science, 13, pp. 195-201.

[12] Camanho, P. P., Dávila, C. G., Pinho, S. T., Iannucci, L. and Robinson, P. (2006) 'Prediction of in situ strengths and matrix cracking in composites under transverse tension and in-plane shear', Composites Part A: Applied Science and Manufacturing, 37(2), pp. 165-176. doi: 10.1016/j.compositesa.2005.04.023.

[13] Pinho, S. T., Iannucci, L. and Robinson, P. (2006) 'Physically-based failure models and criteria for laminated fibre-reinforced composites with emphasis on fibre kinking: Part I: Development', Composites Part A: Applied Science and Manufacturing, 37(1), pp. 63-73. doi: 10.1016/j.compositesa.2005.04.016.

[14] Catalanotti, G. (2019) 'Prediction of in situ strengths in composites: Some considerations', Composite Structures, 207, pp. 889-893. doi: 10.1016/j.compstruct.2018.09.075.

[15] ASTM International (2018) 'ASTM D5766 / D5766M-11(2018), Standard Test Method for Open-Hole Tensile Strength of Polymer Matrix Composite Laminates', Annual Book of ASTM Standards. West Conshohocken, PA, pp. 1-7. doi: 10.1520/D5766_D5766M-11R18. 